Огляди літератури, оригінальні дослідження, погляд на проблему, випадок з практики, короткі повідомлення УДК 616.12-008.318-02:616.127-005.8-06:616.132.2-089.5

DOI 10.11603/1811-2471.2021.v.i2.12055

\title{
АНАЛІЗ ПОРУШЕНЬ РИТМУ У ХВОРИХ НА ІНФАРКТ МІОКАРДА НА ДОГОСПІТАЛЬНОМУ ЕТАПІ ТА В РАННЬОМУ І ПІЗНЬОМУ РЕПЕРФУЗІЙНОМУ ПЕРІОДІ: ОГЛЯД ЛІТЕРАТУРИ ТА ДАНІ ВЛАСНИХ СПОСТЕРЕЖЕНЬ
}

\author{
○Н. В. Бадюк, М. В. Гребеник
}

Тернопільський начіональний медичний університет імені І. Я. Горбачевського МОЗ України

РЕЗЮМЕ. Інфаркт міокарда часто маніфестує складними, фатальними порушеннями ритму, що становить найбільшу загрозу для виживання у перші години розвитку гострої ішемії міокарда. Частота порушень ритму серця (ПРС) істотно відрізняється залежно від етапу госпіталізації та від вчасно проведеного перкутанного коронарного втручання, а їх прогностична оцінка неоднозначна.

Метою даного фрагменту нашого дослідження було проведення аналізу ПРС в різні періоди ІМ та зіставлення їх з даними інших досліджень.

Матеріал і методи. Проведено аналіз даних локального реєстру ІМ кардіологічної клініки кафедри терапії і сімейної медицини ФПО на базі міського кардіоцентру за 2010-2020рр., який охоплює понад 2000 спостережень. Для дослідження відібрано дані 1593 пацієнтів у віці 29-89 років, середній вік $(65,10 \pm 0,37)$ років. За допомогою ліцензованої програми SPSS v.21 проведена статистична обробка даних, вписаних в електронні таблиці Ехсеl 2010. Паралельно за пошуковими системами Pubmed, Google Scholar, Sciencedirect, Webcardio проведено аналіз літературних джерел з даної тематики за останні 10 років.

Результати. ША, такі як ШТ та ФШ, можуть виникати в будь-який час IM, починаючи з ранніх хвилин гострого періоду до віддаленого періоду IM. У 6 \% пацієнтів із ГКС розвиваються ШТ або ФШ у перші години після виникнення симптомів, найчастіше перед госпіталізацією в стаціонар [10]. У нашому дослідженні ША на догоспітальному етапі були зафіксовані у 15,34 \%.

Ранні реперфузійні аритмії у нашому дослідженні виявлено у 32,54 \%, що проявлялись надшлуночковою $(5,7$ \%) та шлуночковою (17,3\%) екстрасистолією, пароксизмами фібриляції передсердь $(1,92$ \%), шлуночковою тахікардією (5,7 \%), фібриляцією шлуночків (1,92\%), що в середньому збігається з даними різних авторів. 3гідно 3 нашими спостереженнями, частка пізніх реперфузійних аритмій становила 12,6 \% у вигляді надшлуночкової $(4,4$ \%) та шлуночкової (4,4\%) екстрасистолії, пароксизмів ФП (1,92 \%) і ША (2,0 \%) здебільшого за рахунок ШТ.

Висновки. Як шлуночкова, так і надшлуночкова аритмії часто зустрічаються на догоспітальному етапі та під час реваскуляризації при IM.

КЛючОВІ СЛОВА: інфаркт міокарда; порушення ритму серця.

Вступ. Інфаркт міокарда (IM) часто маніфестує складними, фатальними порушеннями ритму, що становить найбільшу загрозу для виживання у перші години розвитку гострої ішемії міокарда. Завдяки впровадженню в клінічну практику ранньої реваскуляризації міокарда за останні 10 років виникнення епізодів шлуночкових аритмій (ША), що розвиваються упродовж перших двох діб після IM з підйомом сегмента ST (STEMI), дещо зменшилось, проте деякі дослідження вказують на наявність стійкої ША більш ніж у 5 \% хворих у пререперфузійному періоді STEMI. При цьому встановлено збільшення ризику їх розвитку в випадках, коли перед виникненням IM вже була систолічна дисфункція і / або вогнищевий фіброз міокарда лівого шлуночка (ЛШ) [10]. Фібриляція передсердь (ФП) є найпоширенішою надшлуночковою тахіаритмією, яка може перебігати безсимптомно та / або може бути пов'язана зі швидким погіршенням гемодинаміки, що теж вимагає негайного лікування.

Показником, що визначає прогноз хворого на IM, зазвичай $є$ систолічна функція ЛШ, критичне зниження якої призводить до збільшення ризику раптової серцевої смерті (РСС), що пов'язано з виникненням аритмій у віддаленому післяінфарктному періоді [12]. Проте відомо, що виникнення епізодів порушення ритму серця (ПРС), протягом гострого або підгострого періоду ІМ $є$ більш значущим предиктором РСС. У науковій літературі перелічені досить суперечливі дані відносно прогностичної значущості аритмій, що ускладнили перебіг ГІМ у перші 48 годин. Більшість дослідників вважають, що загальна серцева смертність хворих із ранньою фібриляцією шлуночків (ФШ) достовірно не відрізняється від кількості хворих без ША. Існує одностайна думка дослідників щодо необхідності вторинної профілактики РСС у хворих з ГІМ і епізодом стійкої ША, що виникла через 48 годин [15]. В цілому, частота ПРС істотно відрізняється залежно від етапу госпіталізації та від вчасно проведеного перкутанного коронарного втручання (ПКВ), а їх прогностична оцінка неоднозначна.

Метою даного фрагменту нашого дослідження було проведення аналізу ПРС у різні періоди IM та зіставлення їх з даними інших досліджень

Матеріал і методи дослідження. Проведено аналіз даних локального реєстру IM кардіоло- 
Огляди літератури, оригінальні дослідження, погляд на проблему, випадок з практики, короткі повідомлення гічної клініки кафедри терапії і сімейної медицини ФПО на базі міського кардіоцентру за 20102020 рр., який охоплює понад 2000 спостережень. Для дослідження відібрано дані 1593 пацієнтів у віці 29-89 років, середній вік $(65,10 \pm 0,37)$ років. За допомогою ліцензованої програми SPSS v.21 проведена статистична обробка даних, вписаних в електронні таблиці Excel - 2010. Паралельно за пошуковими системами Pubmed, Google Scholar, Sciencedirect, Webcardio проведено аналіз літературних джерел з даної тематики за останні 10 років.

Результати й обговорення. ША, такі як ШТ та ФШ, можуть виникати в будь-який час IM, починаючи з ранніх хвилин гострого періоду до віддаленого періоду IM. У 6 \% пацієнтів із ГКС розвиваються ШТ або ФШ у перші години після виникнення симптомів, найчастіше передпоступленням в стаціонар [14]. У нашому дослідженні ША на догоспітальному етапі були зафіксовані у 15,34 \%.

Існує невелика кількість даних про вплив догоспітальних ША на віддалені результати у пацієнтів зі STEMI, оскільки у більшості випадків оцінка ПРС методологічно обмежена на догоспітальному етапі [11].

Загальна характеристика ПРС на догоспітальному етапі представлена у досліджуваній когорті пацієнтів та зіставлена з даними літератури у таблиці 1.

Таблиця 1. Порушення ритму серця у догоспітальному періоді інфаркту міокарда, \% (дані власних спостережень та огляду літератури)

\begin{tabular}{|l|c|c|}
\hline \multicolumn{1}{|c|}{ Характер аритмії на догоспітальному етапі } & $\begin{array}{c}\text { За даними огляду літератури, } \\
\%\end{array}$ & $\begin{array}{c}\text { Авторські дані, } \\
\%\end{array}$ \\
\hline Надшлуночкова екстрасистолія & $6[1]$ & 5,7 \\
\hline Шлуночкова екстрасистолія & $93[2]$ & 13,4 \\
\hline Суправетрикулярна тахікардія & - & 1,92 \\
\hline Шлуночкова тахікардія & $1-7[3,4]$ & 11,5 \\
\hline Фібриляція шлуночків & $2-3[5,6]$ & 3,84 \\
\hline Пароксизмальна фібриляція передсердь & $9[7,8]$ & 9,61 \\
\hline Перманентна фібриляція передсердь & $6[7,8]$ & 3,84 \\
\hline
\end{tabular}

Примітка. В квадратних дужках наведені посилання на літературні джерела, представлені в кінці статті.

Як видно з таблиці 1, за більшістю форм аритмії дані подібні. Лише шлуночкова ектопія, за даними Eldar M., Newby K.H., Mont L. et al., виявлена майже у всіх хворих. Слід зауважити, що ми враховували лише часту шлуночкову екстрасистолію, яка була зафіксована на ЕКГ або в записах лікарів, що оглядали пацієнта на догоспітальних етапах, що суттєво обмежує їх інформативність. Крім цього, у представлених літературних посиланнях у більшості випадків застосований аналіз ХМЕКГ. Звісно, що безперервне добове моніторування ЕКГ суттєво відрізняється від повсякденних рутинних методів контролю ритму.

Традиційно вважали, що рання ШТ та ФШ збільшують госпітальну смертність та 30-денну смертність і не впливають на довготривалий ризик. Однак останні дослідження викликають сумніви щодо цих тверджень. Kosmidou I. at al. повідомили, що ранні реперфузійні ША у пацієнтів із STEMI дійсно були пов'язані зі збільшенням 3-річних показників смерті від тромбозу стента. Крім того, клінічний вплив ША при STEMI також залежить від часу виникнення аритмій. Перший епізод ШТ та ФШ, що виникає до, під час або після реперфузії, обтяжується різними показниками смертності, ймовірно, через різні аритмічні механізми та особливості анамнезу пацієнта.
За нашими даними були візуалізовані лише епізоди ФШ в ранній реперфузійний період (1,92\%), усі пацієнти були успішно виписані зі стаціонару, летальних наслідків упродовж 30 днів після виписування зі стаціонару не фіксувалось. На даному етапі важливо вивчати катамнез паці$\epsilon н т і в$, які перенесли ФШ у різні терміни госпітального періоду IM.

Прогностична значимість ранніх реперфузійних ША залишається все ще сумнівною. Більшість авторів повідомили, що ШТ та ФШ, які виникають під час перкутанного втручання (ПКВ), пов'язані з п'ятиразовим збільшенням смертності у стаціонарах та 30-денною смертністю. Навпаки, дослідження PAMI (Первинна ангіопластика IM) не продемонстрували, що шлуночковові аритмії під час ПКВ передбачають найгірший внутрішньолікарняний прогноз [15]. Вплив індукованих реперфузією ША на віддалені результати також $\epsilon$ суперечливим, однак, згідно з більшістю досліджень, цей тип аритмії не пов'язаний зі збільшенням довгострокової смертності [1].

Ранні реперфузійні аритмії у нашому дослідженні виявлено у $32,54 \%$, що проявлялись надшлуночковою $(5,7$ \%) та шлуночковою $(17,3$ \%) екстрасистолією, пароксизмами фібриляції передсердь (1,92 \%), шлуночковою тахікардією (5,7 \%), 
Огляди літератури, оригінальні дослідження, погляд на фібриляцією шлуночків (1,92 \%), що в середньому збігається з даними різних авторів. Дані ПРС були прогностично безпечними на короткому відрізку спостереження.

Пізні реперфузійні аритмії зустрічаються у 1,6-4,4 \% хворих зі STEMI протягом 48 годин після появи симптомів та $\epsilon$ небезпечними $[1,9]$. Опубліковані дані літератури свідчать про те, що стійкі шлуночкові аритмії $€$ предикторами гіршого внутрішньолікарняного прогнозу в умовах гострої ішемії міокарда. Однак специфічного та чіткого зв'язку між типом, терміном ША та застосованими стратегіями лікування, особливо коронарної реваскуляризації та тривалим прогнозом при IM, немає.

Згідно з нашими спостереженнями, частка пізніх реперфузійних аритмій становила 12,6 \% у вигляді надшлуночкової (4,4 \%) та шлуночкової (4,4\%) екстрасистолії, пароксизмів ФП (1,92 \%) ША (2,0 \%) здебільшого за рахунок ШТ.

Прогностичне значення ФП при STEMI тривалий час залишалося суперечливим. Однак в останні роки завдяки аналізу великого числа досліджень, що включали понад 200 тисяч хворих, встановлено, що розвиток ФП пов'язаний зі значним збільшенням смертності [12], зокрема госпітальної, 30-денної, протягом одного року і навіть більше. Однак ці дані не стосуються пацієнтів, у яких ФП виникла у перші 2 дні гострого періоду ІМ.

У нашому дослідженні пароксизми ФП частіше виникали на догоспітальному етапі. Хронічна ФП діагностована у 3,84 \% пацієнтів зі STEMI. Згідно з нашими дослідженнями, у хворих із ФП ІМ частіше ускладнювався кардіогенним шоком і набряком легень ( $<<0,001)$. У хворих на IM, усклад-
ФП, встановлена кореляція з летальністю у перші 30 діб ( $r=0,128, p<0,001)$ і віддаленою смертністю $(r=0,148, p<0,001)$.

Ризик зупинки серця та раптової серцевої смерті залишається підвищеним після IM та вважається найвищим у перші 30 днів (1,2-2,3 \%). ФШ та / або поліморфна ШТ частіше викликаються гострою ішемією, і тому вони можуть бути показником неповної реперфузії або рецидиву ішемії після первинного ПКВ (наприклад, гострий тромбоз стента), тоді як мономорфна ШТ найчастіше пов'язана з наявністю попередньо аритмогенного субстрату (наприклад, рубця міокарда) [12]. Нещодавно продемонстровано, що віддалена смертність після STEMI була передбачена догоспітальними та післяреперфузійними ША, тоді як реперфузійні ША не впливали на 5-річний період виживання [13].

Висновки. Як шлуночкова, так і надшлуночкова аритмії часто трапляються на догоспітальному етапі та під час реваскуляризації при IM. Час появи та діагностика аритмії $є$ основними детермінантами прогностичного впливу аритмії.

Перспективи подальших досліджень. Зараз ми вивчаємо катамнез пацієнтів з пізніми реперфузійними аритміями для оцінки віддаленого прогнозу, оскільки відомо, що серед пацієнтів 3 IM пацієнти з раннім розвитком ФШ / ШТ мають більший ризик 30-денної смертності (22 \% у порівнянні з 5 \%), ніж пацієнти без ФШ / ШТ [16]. На сьогодні $є$ очевидним, що своєчасна невідкладна реваскуляризація, разом із оптимальною медикаментозною терапією, є ключовими в запобіганні фатальним аритміям в умовах гострої ішемії міокарда.

\section{ЛІТЕРАТУРА}

1. Prognostic significance of complex ventricular arrhythmias complicating ST-segment elevation myocardial infarction / T. Podolecki, R. Lenarczyk, J. Kowalczyk [et al.] / The American Journal of Cardiology. - 2018. Vol. 121. - P. 805-809.

2. Ventricular arrhythmias in ischemic heart disease: mechanism, prevalence, significance, and management / J. T. Bigger, F. J. Dresdale, R. H. Heissenbuttel [et al.] // Progress in Cardiovascular Diseases. - 1977. Vol. 19. - P. 255-300.

3. Primary ventricular tachycardia in acute myocardial infarction: clinical characteristics and mortality / M. Eldar, Z. Sievner, U. Goldbourt [et al.] // Annals of Internal Medicine. - 1992. - Vol. 117. - P. 31-36.

4. Significance of arrhythmias during the first 24 hours of acute myocardial infarction treated with alteplase and effect of early administration of a beta-blocker or a bradycardiac agent on their incidence / H. Heidbüchel,
J. Tack, L. Vanneste [et al.] // Circulation. - 1994. - Vol. 89. P. 1051-1059.

5. Sustained ventricular arrhythmias in patients receiving thrombolytic therapy: incidence and outcomes. The GUSTO Investigators / K. H. Newby, T. Thompson, A. Stebbins [et al.] // Circulation. - 1998. - Vol. 98. - P. 2567-2573.

6. Predisposing factors and prognostic value of sustained monomorphic ventricular tachycardia in the early phase of acute myocardial infarction / L. Mont, J. Cinca, P. Blanch // Journal of the American College of Cardiology. 1996. - Vol. 28. - P. 1670-1676.

7. Cardiac arrhythmias in acute coronary syndromes: position paper from the joint EHRA, ACCA, and EAPCI task force / B. Gorenek, L. C. Blomström, B. J. Terradellas [et al.] // Europace. - 2014. - Vol. 16. - P. 1655-1673.

8. Prevalence and significance of accelerated idioventricular rhythm in patients with ST-elevation myocardial infarction treated with primary percutaneous coronary 
Огляди літератури, оригінальні дослідження, поглядна intervention / C. J. Terkelsen, J. T. Sørensen, A. K. Kaltoft [et al.] // Journal of the American College of Cardiology. 2009. - Vol. 104. - P. 1641-1646.

9. Prognostic significance of postprocedural sustained ventricular tachycardia or fibrillation in patients undergoing primary percutaneous coronary intervention (from the HORIZONS-AMI Trial) / R. H. Mehta, Yu. Jennifer, J. P. Piccini [et al.] // American Journal of Cardiology. 2012. - Vol. 109. - P. 805-812.

10. ESC Guidelines for the management of patients with ventricular arrhythmias and the prevention of sudden cardiac death / S. G. Priori, C. Blomstrom-Lundqvist, A. Mazzanti [et al.] // Europace. - 2015. - Vol. 17. - P. 1601-1687.

11. Cardiac arrhythmias in the emergency settings of acute coronary syndrome and revascularization: an European Heart Rhythm Association (EHRA) consensus document, endorsed by the European Association of Percutaneous Interventions (EAPCI), and European Acute Cardiovascular Care Association (ACCA) / Z. Kalarus, J. H. Svendsen, D. Capodanno [et al.] // EP Europace. - 2020. - Vol. 21. - P. 1603-1604.

12. 2017 ESC Guidelines for the management of acute myocardial infarction in patients presenting with ST-segment elevation: the Task Force for the management of acute myocardial infarction in patients presenting with ST- проблему, випадок з практики, короткі повідомлення segment elevation of the European Society of Cardiology (ESC) / B. Ibanez, S. James, S. Agewall [et al.] // European Heart Journal. - 2018. - Vol. 39. - P. 119-177.

13. Priori S. G. 2015 ESC Guidelines for the management of patients with ventricular arrhythmias and the prevention of sudden cardiac death / S. G. Priori, C. Blomström-Lundqvist // European Heart Journal. - 2015. - Vol. 36. - P. 2793-2867.

14. Incidence of sudden cardiac death after ventricular fibrillation complicating acute myocardial infarction: a 5 year cause of death analysis of the FAST MI 2005 registry / W. Bougouin, E. Marijon, E. Puymirat // European Heart Journal. - 2014. - Vol. 35. - P. 116-122.

15. Белик В. Е. Гликемия при поступлении и особенности госпитального периода у больных с инфарктом миокарда с подъемом сегмента ST / В. Е. Белик, О.В. Груздева, В. Н. Каретникова // Сибирский медицинский журнал. - 2014. - № 4. - С. 25-28.

16. The association between early ventricular arrhythmias, renin-angiotensin-aldosterone system antagonism, and mortality in patients with ST-segmentelevation myocardial infarction: Insights from Global Use of Strategies to Open coronary arteries (GUSTO) V / A. T. Askari, M. H. Shishehbor, M. A. Kaminski [et al.] // American Heart Journal. 2009. - Vol. 158. - P. 238-243.

\section{REFERENCES}

1. Podolecki, T., Lenarczyk, R., Kowalczyk, J., Jedrzejczyk-Patej, E., Chodor, P., Mazurek, M., \& Kalarus, Z. (2018). Prognostic significance of complex ventricular arrhythmias complicating ST-segment elevation myocardial infarction. The American Journal of Cardiology, 121, 805-809. https://doi.org/10.1016/j.amjcard.2017.12.036

2. Bigger, J.T., Dresdale, F.J., Heissenbuttel, R.H., Weld, F.M., \& Wit, A.L. (1977). Ventricular arrhythmias in ischemic heart disease: mechanism, prevalence, significance, and management. Progress in Cardiovascular Diseases, 19, 255-300.

3. Eldar, M., Sievner, Z., Goldbourt, U., Reicher, R.H., Kaplinsky, E., \& Behar, S. (1992). Primary ventricular tachycardia in acute myocardial infarction: clinical characteristics and mortality. Annals of Internal Medicine, 117, 31-36. https://doi.org/10.7326/0003-4819-117-1-31

4. Heidbüchel, H., Tack, J., Vanneste, L., Ballet, A., Ector, H., \& Werf, V.F. (1994). Significance of arrhythmias during the first 24 hours of acute myocardial infarction treated with alteplase and effect of early administration of a beta-blocker or a bradycardiac agent on their incidence. Circulation, 89, 1051-1059. https://doi.10.1161/01. cir.89.3.1051

5. Newby, K.H., Thompson, T., Stebbins, A., Topol, E.J., Califf, R.M., \& Natale, A. (1998). Sustained ventricular arrhythmias in patients receiving thrombolytic therapy: incidence and outcomes. The GUSTO Investigators. Circulation, 98, 2567-2573. https://doi.10.1161/01.cir.98.23.2567

6. Mont, L., Cinca, J., Blanch, P., Blanco, J., Figueras, J., Brotons, C., \& Soler-Soler, J. (1996). Predisposing factors and prognostic value of sustained monomorphic ventricular tachycardia in the early phase of acute myocardial infarc- tion. Journal of the American College of Cardiology, 28, 16701676. https://doi.org/10.1016/S0735-1097(96)00383-X

7. Gorenek, B., Blomström, L.C, Terradellas, B.J., Camm, A.J., Hindricks, G., Huber, K., \& Savelieva, I. (2014). Cardiac arrhythmias in acute coronary syndromes: position paper from the joint EHRA, ACCA, and EAPCI task force. Europace, 16, 1655-1673. https://doi: 10.1093/europace/ euu208

8. Terkelsen, C.J., Sørensen, J.T., Kaltoft, A.K., Nielsen, S.S., Thuesen, L., Bøtker, H.-E., \& Lassen, J.F. (2009). Prevalence and significance of accelerated idioventricular rhythm in patients with ST-elevation myocardial infarction treated with primary percutaneous coronary intervention. The American Journal of Cardiology, 104, 1641-1646. https:// doi.org/10.1016/j.amjcard.2009.07.037

9. Mehta, R.H., Jennifer, Yu., Piccini, J.P., Tcheng, J.E., Farkouh, M.E., Reiffel, J., \& Gregg, W. (2012). Stone Prognostic significance of postprocedural sustained ventricular tachycardia or fibrillation in patients undergoing primary percutaneous coronary intervention (from the HORIZONS-AMI Trial). The American Journal of Cardiology, 109, 805-812. https://doi: 10.1016/j.amjcard.2011.10.043

10. Priori, S.G., Blomstrom-Lundqvist, C., Mazzanti A., Blom, N., Borggrefe, M., Camm, J., \& Veldhuisen, D.J. (2015). ESC Guidelines for the management of patients with ventricular arrhythmias and the prevention of sudden cardiac death. Europace, 17, 1601-1687. https://doi.org/10.1093/ eurheartj/ehv316

11. Kalarus, Z., Svendsen, J.H., Capodanno, D., Dan, G.-A., Maria, E., Gorenek, B., Jędrzejczyk-Patej, E., \& Berti, S. (2020). Cardiac arrhythmias in the emergency settings of acute coronary syndrome and revascularization: an European Heart 
Огляди літератури, оригінальні дослідження, погляд на проблему, випадок з практики, короткі повідомлення Rhythm Association (EHRA) consensus document, endorsed by the European Association of Percutaneous Cardiovascular Interventions (EAPCI), and European Acute Cardiovascular Care Association (ACCA). EP Europace, 21, 1603-1604. https://doi.org/10.1093/europace/euz163

12. Ibanez, B., James, S., Agewall, S., Antunes, M.J., Bucciarelli-Ducci, C., Bueno, H. \& Widimský, P. (2018). 2017 ESC Guidelines for the management of acute myocardial infarction in patients presenting with ST-segment elevation: the Task Force for the management of acute myocardial infarction in patients presenting with ST-segment elevation of the European Society of Cardiology (ESC). European Heart Journal, 39, 119-177. https://doi.org/10.1093/eurheartj/ehx393

13. Priori, S.G., \& Blomström-Lundqvist, C. (2015). 2015ESC Guidelines for the management of patients with ventricular arrhythmias and the prevention of sudden cardiac death. European Heart Journal, 36, 2793-2867. https:// doi:10.1093/eurheartj/ehv316

14. Bougouin, W., Marijon, E., Puymirat, E., Defaye, P., Celermajer, D. S., Heuzey, J.-Y., \& Danchin, N. (2014). Inci-

dence of sudden cardiac death after ventricular bbrillation complicating acute myocardial infarction: a 5 year cause of death analysis of the FAST MI 2005 registry. European Heart Journal, 35, 116-122. https://doi: 10.1093/eurheartj/ eht453

15. Belyk, V.E., Gruzdeva, O.V., \& Karetnykova, V.N. (2014). Glikemiya pri postuplenii I osobenosti gospitalnogo perioda u bolnykh s infarktom miokarda s podiomom sigmenta ST [Glycemia on admission and the characteristics of the hospital period in patients with ST-segment elevation myocardial infarction]. Sibirskiy Meditsynskiy zhurnal- Siberian Medical Journal, 4, 25-28 [in Russian].

16. Askari, A.T., Shishehbor, M.H., Kaminski, M.A., Riley, M.J., Hsu, A., \& Lincoff, A.M. (2009). The association between early ventricular arrhythmias, renin-angiotensinaldosterone system antagonism, and mortality in patients with ST-segmentelevation myocardial infarction: Insights from Global Use of Strategies to Open coronary arteries (GUSTO) V. American Heart Journal, 158, 238-243. https:doi: 10.1016/j.ahj.2009.05.023

\title{
АНАЛИЗ НАРУШЕНИЙ РИТМА У БОЛЬНЫХ ИНФАРКТОМ МИОКАРДА НА ДОГОСПИТАЛЬНОМ ЭТАПЕ И В РАННЕМ, ПОЗДНЕМ РЕПЕРФУЗИОННОМ ПЕРИОДЕ: ОБЗОР ЛИТЕРАТУРЫ И ДАННЫЕ СОБСТВЕННЫХ НАБЛЮДЕНИЙ
}

\author{
๑Н. В. Бадюк, М. В. Гребеник
}

Тернопольский национальный медицинский университет имени И. Я. Горбачевского МОз Украины

РЕЗЮМЕ. Инфаркт миокарда часто манифестирует сложными, роковыми нарушениями ритма сердца, представляет большую угрозу для выживания в первые часы развития острой ишемии миокарда. Частота нарушений ритма сердца (HPC) существенно отличается в зависимости от этапа госпитализации и от вовремя проведенного ПКВ, а их прогностическая оценка неоднозначна.

Целью данного фрагмента нашего исследования было проведение анализа ПРС в разные периоды ИМ и сопоставление их с данными других исследований.

Материал и методы. Проведен анализ данных локального реестра ИМ кардиологической клиники кафедры терапии и семейной медицины ФПО на базе городского кардиоцентра за 2010-2020 гг., который охватывает более 2000 наблюдений. Для исследования отобраны данные 1593 пациентов в возрасте 29-89 лет, средний возраст $(65,10 \pm 0,37)$ лет. С помощью лицензированной программы SPSS v.21 проведена статистическая обработка данных, вписанных в электронные таблицы Excel - 2010. Параллельно по поисковым системам Pubmed, Google Scholar, Sciencedirect, Webcardio проведен анализ литературных источников по данной тематике за последние 10 лет.

Результаты. ЖА, такие как ЖТ и ФЖ, могут возникать в любое время ИМ, начиная с ранних минут острого периода до отдаленного периода ИМ. У 6 \% пациентов с ОКС развиваются ЖТ или ФЖ в первые часы после возникновения симптомов, чаще всего перед поступлением в стационар [10]. В нашем исследовании ЖА на догоспитальном этапе были зафиксированы у 15,34 \%.

Ранние реперфузионные аритмии в нашем исследовании выявлены у 32,54 \%, что проявлялось наджелудочковой $(5,7$ \%) и желудочковой (17,3 \%) экстрасистолией, пароксизмами фибрилляции предсердий $(1,92$ \%), желудочковой тахикардией (5,7 \%), фибрилляцией желудочков (1,92 \%), что в среднем совпадает с данными различных авторов. Согласно нашим наблюдениям, доля поздних реперфузионных аритмий составила 12,6 \% в виде наджелудочковой $(4,4 \%)$ и желудочковой $(4,4$ \%) экстрасистолии, пароксизмов ФП $(1,92 \%)$ ША $(2,0 \%)$, в основном за счет Шт.

Выводы. Как желудочковая, так и наджелудочковая аритмии часто встречаются на догоспитальном этапе и во время реваскуляризации при ИМ. Время появления и диагностика аритмии являются основными детерминантами прогностического влияния аритмии.

КЛЮЧЕВЫЕ СЛОВА: инфаркт миокарда; нарушение ритма сердца. 
Огляди літератури, оригінальні дослідження, погляд на проблему, випадок з практики, короткі повідомлення

\section{ANALYSIS OF RHYTHM DISORDERS IN PATIENTS WITH MYOCARDIAL INFARCTION IN THE PREHOSPITAL STAGE AND IN THE EARLY AND LATE REPERFUSION PERIOD: A REVIEW OF LITERATURE}

@N. V. Badiuk, M. V. Hrebenyk

\section{Horbachevsky Ternopil National Medical University}

SUMMARY: Myocardial infarction (MI) often manifests as complex, fatal arrhythmias, which is the greatest threat to survival in the first hours of acute myocardial ischemia. The frequency of cardiac arrhythmias (CA) differs significantly depending on the stage of hospitalization, time when percutaneous coronary intervention (PCI) was conducted and their prognostic assessment is ambiguous.

The aim - to analyze the CA in different periods of MI and compare them with data from other studies.

Material and Methods: the analysis of the local MI register conducted by the department of therapy and family medicine on the basis of the city cardiological center from 2010 to 2020 years which includes more than 2000 clinical cases. Data from 1593 patients aged 29-89 years, mean age (65.10 \pm 0.37$)$ years were selected for the study. Statistical processing of data was performed with SPSS v.21 and Microsoft Excel - 2010. At the same time the search engines such as Pubmed, Google Scholar, Sciencedirect, Webcardio were used to analyse literature sources for the last 10 years.

Results. Ventricular arrhythmia (VA) such as ventricular tachycardia (VT) and AF can occur at any time during myocardial infarction, from the early minutes of the acute period to the distant period of MI. $6 \%$ of patients with acute coronary syndrome (ACS) develop VT or atrial fibrillation (AF) in the first hours after the onset of symptoms, more often before admission to the hospital [10]. In our study, VA at the prehospital stage were recorded in $15.34 \%$.

Early reperfusion arrhythmias in our study were found in $32.54 \%$, manifested by supraventricular (5.7 \%) and ventricular (17.3\%) extrasystoles, paroxysms of AF (1.92\%), VT (5.7\%), ventricular fibrillation (1.92 \%), which on average coincides with the data of various authors. According to our observations, late reperfusion arrhythmias were observed in $12.6 \%$ of cases in the form of supraventricular (4.4\%) and ventricular (4.4\%) extrasystoles, paroxysms of AF (1.92 \%) of VA $(2.0 \%)$ mainly due to VT.

Conclusions: Both ventricular and supraventricular arrhythmias often occur in the prehospital stage and during revascularization in MI.

KEY WORDS: myocardial infarction; cardiac arrhythmia. 